\title{
Increased bone alkaline phosphatase levels do not necessarily cause hypermineralization per se
}

\author{
Christopher Sharp and Per Magnusson \\ Journal Article
}

\section{Tweet}

N.B.: When citing this work, cite the original article.

Original Publication:

Christopher Sharp and Per Magnusson, Increased bone alkaline phosphatase levels do not necessarily cause hypermineralization per se, Bone, 2016. 89(), pp.83-84.

http://dx.doi.org/10.1016/j.bone.2015.05.044

Copyright: Elsevier

http://www.elsevier.com/

Postprint available at: Linköping University Electronic Press

http://urn.kb.se/resolve?urn=urn:nbn:se:liu:diva-134469
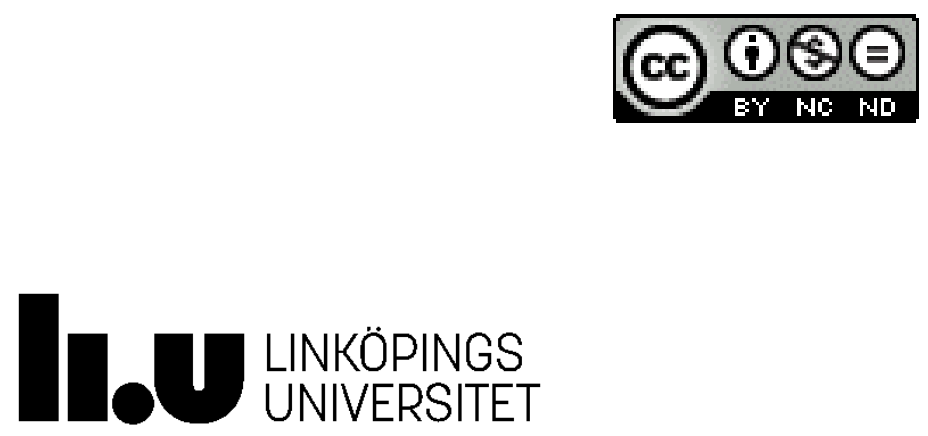
Journal: BONE

Letter to the Editor

\title{
Increased bone alkaline phosphatase levels do not necessarily cause hypermineralization per se
}

\author{
Christopher A. Sharp ${ }^{\mathrm{a}}$ and Per Magnusson ${ }^{\mathrm{a}^{*}}$
}

a Department of Clinical Chemistry and Department of Clinical \& Experimental Medicine, Linköping University, SE-581 85 Linköping, Sweden

* Corresponding author:

Per Magnusson, Ph.D., Professor

Department of Clinical Chemistry

Department of Clinical \& Experimental Medicine

Linköping University

SE-581 85 Linköping

Sweden

Tel: +46101033997

Fax: +46101033240

E-mail: per.magnusson@regionostergotland.se

Keywords: Bone; Alkaline phosphatase; Mineralization; Bone turnover markers; Diabetes mellitus Abbreviations: BALP, bone-specific alkaline phosphatase; BTMs, bone turnover markers 
Dear Editor,

Diminished bone health and increased risk of fracture is increasingly recognised as a complication of diabetes mellitus and even as a consequence of its management. We read with interest the recently published review by Starup-Linde and Vestergaard [1] about bone turnover markers (BTMs) in patients with types 1 and 2 diabetes mellitus and their value in assessing bone health in diabetic patients. In brief, 611 eligible studies were identified of which 47 were included: 1 meta-analysis, 29 cross-sectional, 13 randomized controlled trials and 4 longitudinal studies. They concluded that most BTMs had a tendency to be lower in diabetes with the exception of bone-specific alkaline phosphatase (BALP) that were reported to be either within or above the reference interval. This outcome, they suggest, explains the hypermineralized bone matrix and bone quality changes (low bone strength but increased bone mineral density) reported in diabetic patients. We welcome this timely review and wish to comment on their conclusions relating to BALP and bone mineralization, and to discuss possible alternative explanations for their findings.

In mineralizing tissues, the group of BALP isoforms and other phosphatases function in the early stages of mineralization [2]. Hence, measurements of BALP are related to, and reflect the mineralization process, as inferred in their review. The current concept describes osteogenesis as three spatially and chronologically orchestrated events; proliferation with collagen synthesis, extracellular matrix maturation and mineralization based on in vitro studies that show a sequential expression of genes during osteoblast differentiation. Messenger RNA of type I collagen appears first, followed by BALP and then osteocalcin in a controlled process regulated by negative feedback mechanisms [3]. Overall, we view mineralization of bone matrix as a complex process with a multitude of feedback loops, including mechanical inputs. At the tissue level, biological mineralization density has a small variance with optimal values being determined by mechanical loading and defined by the anatomical location of the bone packets within the skeleton [4]. 
An under-mineralized matrix could well lead to attenuation of the feedback signal that "turns off" BALP expression; hence bone cells would express more BALP to achieve greater local mineralization. This process is nicely illustrated in cases of childhood rickets and osteomalacia where poorly mineralized bone is associated with markedly elevated circulating BALP levels that decrease during bone healing $[5,6]$. Additional information on the mineralization state of bone in patients with type 2 diabetes mellitus has been provided by bone histomorphometric indices that demonstrate significantly reduced amount of mineralizing surface and lower bone formation rate in comparison with age-matched non-diabetic controls (Figure) [7].

As suggested in the review by Starup-Linde and Vestergaard [1], states of bone hypermineralization undoubtedly exist [8]. Whether or not elevated BALP levels can convincingly explain reported differences in bone quality is, in our opinion, open to question. BTMs can, and in many cases do, provide the clinician with an overall view of bone remodelling and have considerable value in clinical medicine. However, we caution the over interpretation of circulating BTMs and their mechanistic value and increased serum BALP levels as evidence for hypermineralization of bone.

\section{Conflict of interest statement}

The authors have no conflict to disclose. 


\section{References}

[1] Starup-Linde J, Vestergaard P. Biochemical bone turnover markers in diabetes mellitus - a systematic review. Bone 2015, doi: 10.1016/j.bone.2015.02.019.

[2] Millán JL. The role of phosphatases in the initiation of skeletal mineralisation. Calcif Tissue Int 2013;93:299-306.

[3] Stein GS, Lian JB, Stein JL, Van Wijnen AJ, Montecino M. Transcriptional control of osteoblast growth and differentiation. Physiol Rev 1996;76,593-629.

[4] Roschger P, Paschalis EP, Fratzl P, Klaushofer K. Bone mineralization density distribution in health and disease. Bone 2008;42:456-66.

[5] Oginni LM, Sharp CA, Badru OS, Risteli J, Davie MWJ, Worsfold M. Radiological and biochemical resolution of nutritional rickets with calcium. Arch Dis Child 2003;88:812-17.

[6] Faibish D, Gomes A, Boivin G, Binderman I, Boskey A. Infrared imaging of calcified tissue in bone biopsies from adults with osteomalacia. Bone 2005;36:6-12.

[7] Manavalan JS, Cremers S, Dempster DW, Zhou H, Dworakowski E, Kode A, Kousteni S, Rubin MR. Circulating osteogenic precursor cells in type 2 diabetes mellitus. J Clin Endocrinol Metab 2012;97:3240-50.

[8] Ferguson VL, Bushby AJ, Boyde A. Nanomechanical properties and mineral concentration in articular calcified cartilage and subchondral bone. J Anat 2003;203:191-202. 


\section{Figure Legend}

Histomorphometric changes in bone formation. Tetracycline double-labelled bone biopsies in a Caucasian woman (58 years) with type 2 diabetes mellitus (left) and a Caucasian female control (57 years) (right). Bone formation is decreased in type 2 diabetes mellitus with reduced mineralizing surface. The arrows highlight tetracycline uptake in the control subject and the absence of uptake in the diabetic subject. Adapted with permission from [7]. 

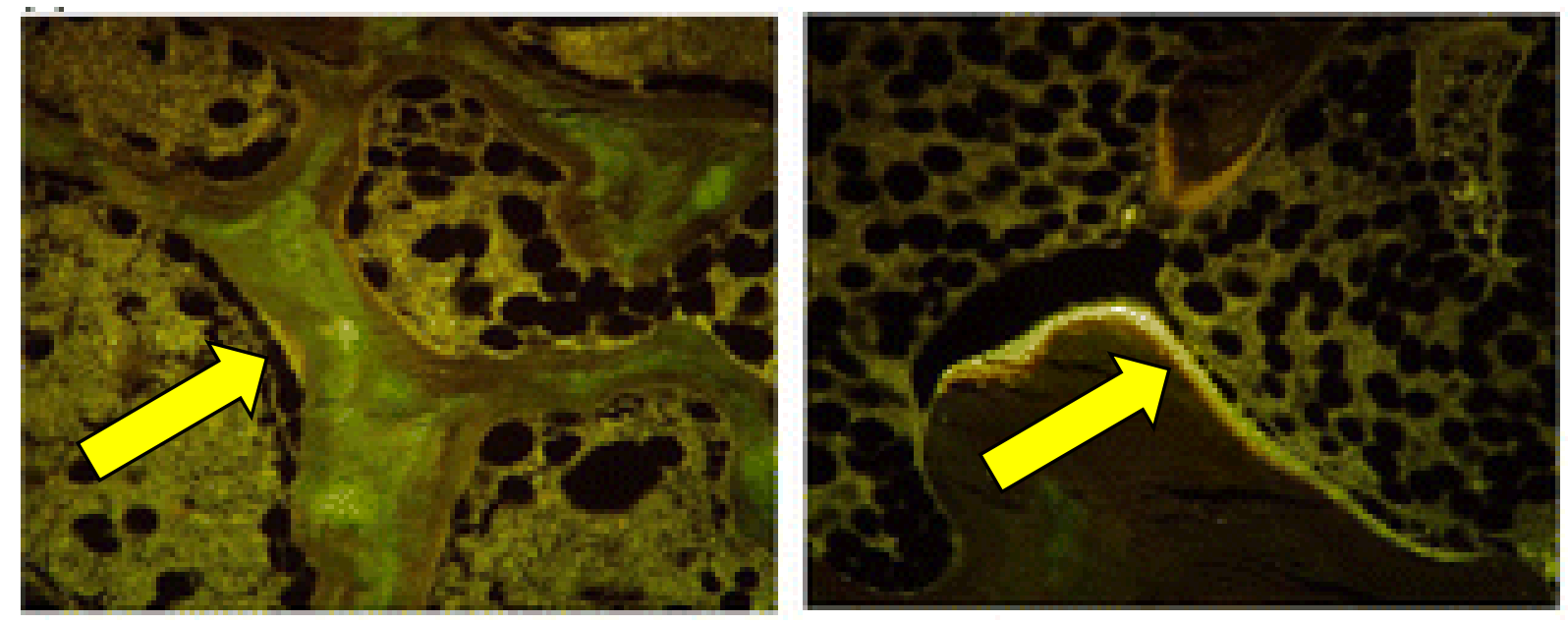